\title{
Indonesian Language Portfolio in Elementary Schools Based on C++, C\# and MySQL Server
}

\author{
Ferril Irham Muzaki
}

'Department of Preschool and Primary Education Faculty of Education, Universitas Negeri Malang, Indonesia

\author{
Article Info \\ Volume 7, Issue 6 \\ Page Number: 265-272 \\ Publication Issue :
}

November-December-2020

\section{Article History}

Accepted : 15 Nov 2020

Published : 02 Dec 2020 Corresponding Author :

\section{ABSTRACT}

The form of programming applications based on $\mathrm{C}++$ and $\mathrm{C} \#$ lies in the design of portfolio-based assessment that is more functional and has high flexibility in terms of developing programming directions. The objectives of this study are (1) measuring infrastructure readiness from authentic use digital database -based assessment, (2) measuring software availability and (3) measuring the availability of spare parts for hardware in the implementation of authentic digital based assessment. The method used is big data analysis from various website. The results of this study (1) the application of authentic assessment digitally based, would be implemented if use storage portfolio, (2) for portfolio analysis can use fuzzy logic combined with the programming language $\mathrm{C}++$ and (3) the use of analytics to the data analysis of the pattern in the portfolio can be used for error analysis in formal grammar. It is suggested to policymakers to redesign the use of fuzzy logic in analytic design for data pattern analysis in student portfolios. The $\mathrm{C}$ \# based application development for learning management system scoring is part of developing creative writing skills. : C ++, C\#, MySQL Server, Object Based Programming, Language Assessment,

\section{INTRODUCTION}

Learning management system-based learning has a role in developing a scoring system. The development of a scoring-based learning management system focuses more on the design for developing standalonebased applications using $C \#$ and or developing $\mathrm{C}$ \#based applications that are compiled with the MySQL server application to make it online.
Hoddie and Parder (2020: 27) explain that developing a learning management system scoring application requires server design and answer database design in the form of a grid. The server is designed to follow the interaction direction of the website which develops the ability to interact. In contrast to $\mathrm{C} \#$ based applications which are designed to follow the direction of developing skills from the design of an application. 
Table 1. The Element of Portfolio Based Language Teaching

\begin{tabular}{lll}
\hline Appreciate the Community Symbol & $\begin{array}{l}\text { Comprehend the Speech } \\
\text { Performances }\end{array}$ & Understand the Speech Circles \\
\hline $\begin{array}{l}\text { Eager to assistance others. } \\
\text { Consume adequate skill in the }\end{array}$ & $\begin{array}{l}\text { Taking views that fit the size } \\
\text { Existence able to see all } \\
\text { community arena }\end{array}$ & $\begin{array}{l}\text { Struggle to recover skills } \\
\text { Identify the successes of other } \\
\text { Planned thoughtful rendering to }\end{array}$ \\
$\begin{array}{l}\text { situations } \\
\text { Responsibility painstaking intelligent } \\
\text { near actions that occur }\end{array}$ & $\begin{array}{l}\text { Contemplate and turn rendering } \\
\text { to bulk }\end{array}$ & $\begin{array}{l}\text { Be an innovator of confident } \\
\text { communitities }\end{array}$ \\
\hline
\end{tabular}

\section{LITERATURE REVIEW}

Dudin, et all (2016: 156) gives an opinion in this case, the use of fuzzy logic is more designed as an analytical tool that issues data analysis that is used to test a student's learning achievement. To make use of fuzzy logic, a student even though asked to upload various kinds of activities and achievements in a database, then the system works to analyze the data pattern of the student portfolio. Designing an adequate analysis system, the use of analytics is useful for analyzing the data entered by students in a database, this must be developed as an initial ingredient in judgment -based decisions made based on an assessment.

\section{METHOD}

The method that is being used is a method Dick and Carrey (2009). This research has been stop in analysis stage due to technological bias.

\section{RESULTS}

\subsection{Infrastructure Readiness from Digital Based} Assessment
This study uses ethnographic study methods as a basis for determining the exact characteristics of authentic use assessment by with $\mathrm{C}++$ and $\mathrm{C} \#$ programming language. The method for data collection is triangulation based on documentary studies, literature review and observation. The collected data synthesized with literature-based research which included expert interviews, internet literature studies and video-based review studies on YouTube and Netflix.

\subsection{Software Avaibility}

\subsubsection{C ++ Language Programming for Character Based Language Teaching}

Nowadays, the use of $\mathrm{C}++$ language programming has been widely using in various purposes, such as games, entertainment, and other purposes. The key points of $\mathrm{C}++$ language program is it is able to learn autodidacts and able to learn via YouTube. Chatterjee, et al. (2014: $24)$. Thus, there are a lot of various purposes for $\mathrm{C}++$ language programming. Once, the purposes for $\mathrm{C}++$ language programming is to build a website that is able to store and manage the data into a single database. On the other perspective, the $\mathrm{C}++$ language programming is constructed to build a single key point, enhance related with Php Script that mostly related on server management on script. 
Table 2. The Element of Self Control in Language Teaching on Elementary Schools

\begin{tabular}{|c|c|c|}
\hline Period Examination & Community Analysis & Multi-Dimensional Analysis \\
\hline Studying ecological situations & $\begin{array}{l}\text { Active with situations in the } \\
\text { atmosphere }\end{array}$ & Being pro community \\
\hline Motivate others & $\begin{array}{l}\text { Talented to set expression } \\
\text { elections }\end{array}$ & $\begin{array}{l}\text { Act intelligently acclimatize to } \\
\text { the atmosphere }\end{array}$ \\
\hline Having the skill to regulate & $\begin{array}{l}\text { Having feelings that alter to other } \\
\text { persons }\end{array}$ & Bright to performance properly \\
\hline $\begin{array}{l}\text { Doing intelligent about ordinary } \\
\text { spectacles }\end{array}$ & Able to grasp backbone & Talented to reflect strategically \\
\hline
\end{tabular}

According to Azar, et al (2015: 4) therefore, the design for ICT for young learners have to have occurred within the topic. On the other hand, the various design of artificial intelligence nowadays has intended to track back on the various technologies. On the other words, the Artificial Intelligence technology has given on the design of various activities. However, the design for language assessment has to be designed with the appropriate language programming. Once, the design for language assessment to analyze the data is using $\mathrm{C}$ ++ language program. Thus, the $\mathrm{C}++$ have to occur in the design on language and tracking of the students' habits and activities.

\subsubsection{C \# Programming Language as Objective Based Programming}

Vancsics, Szatmári and Beszédes (2020) explains C \# based object-based programming is a programming design that focuses on the ability to interact with other programming languages. The development of objectbased programming based on $\mathrm{C}$ \# lies in the ability designing algorithms. Algorithm design is designed using an algorithm that puts forward the design. Another algorithm flow puts forward the ability designing data structures. The $\mathrm{C}$ \# programming language is a development from $\mathrm{C}$ which prioritizes the ability designing an application.

Application planning lies in two things, namely the ability designing data flows and the skills behavior from the data itself. This capability is closely related to object-based programming based on the $\mathrm{C}$ \# programming language.

The design of $\mathrm{C} \#$ based object-based programming rests on the skills to develop a programming language. Codification of $\mathrm{C}$ \# based programming language is closely related to programming based on data flow behavior. C \#-based programming language was developed based on object behavior which emphasizes the programmer's ability to read the target of the programming. Szabo and Nehéz (2019: 68) explains to develop a programming language closely related to the design of optimal application narratives. The development of the $\mathrm{C} \#$ programming language also relies on the ability to develop the characteristics of the data structure. Galowicz (2017) describe the data developed by following the $\mathrm{C}$ \# programming language 
to support the sustainability of the application. The ability to do web design is closely related designed application behavior to make it easier to interpret.

Object based programming for $\mathrm{C}$ \# consists of coded programming steps. $\mathrm{C}$ \# programming for steps that design fuzzy logic in developing programming languages. Korkin and Lyapustin (2019: 110) explaining the $\mathrm{C} \#$ language also puts forward the basics of programming based on interactive web design.

The example of codes is written below based on to Wolf and Henley (2017)

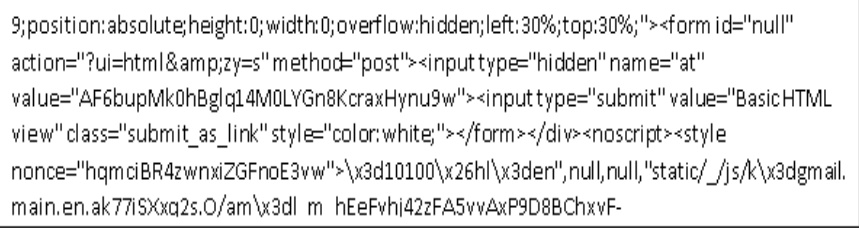

C \# programming puts forward the ability to do calculus based. The logic in calculus is designed to follow the thinking that exists in artificial intelligence. Thoughts that are made in artificial intelligence even though they put forward the ability of neural programming based on skills to do remote access in programming language. Šmitek (2020) explain that $\mathrm{C}$ \#-based programming also puts forward the ability to create applications that are designed to facilitate creativity in designing appropriate logic systems.

\subsection{Availability of Spare Parts for Hardware in The}

Implementation of Authentic Digital Based

Assessment

\subsubsection{React Native Comparison with C \# Programming Language}

React Native-based programming focuses more on elements that build interface interactions. Šmitek(2020) explains that the design of an application interface prioritizes the function of logic rather than the function in developing the application. The $\mathrm{C} \#$ programming language focuses more on the ability to make applications that are more purposeful. The ability to make applications more focused on the skills to develop steps in the learning management system. React native based application design prioritizes the ability to write in comments from a post. The React Native application is more developed in utilizing programming functions that prioritize the ability create the ideal system. In this case, $\mathrm{C}$ \# based applications function more as standalone apps.

Gal (2018) explains that C \# programming focuses more on the accuracy of the functions that exist in an application. Application development for C \# programming is mostly developed based on the design and involvement of interface applications. Interface application design puts forward the ability and skills to do web design.

The example of codes is written below based on to Wolf and Henley (2017):

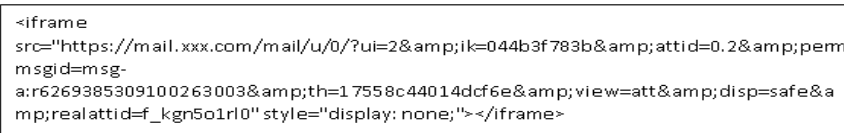

The development of interface design is closely related to the skills that give the ability for application data. Data are interacted and designed scheming adequate programming facts. The development of the interface application focuses more on developing skills to develop data and adequate interactions between data structures. Application development for $\mathrm{C} \#$ is more focused on developing the design principles of an adequate application.

Gal (2018) explains that users have a major role in utilizing $\mathrm{C}$ \# based applications. Application developers develop applications based on requests from users. C \# 
Developed and Tested for User Convenience. Online and hybrid application development has different development directions. C \# development for Standalone Apps has a focus on hard disk capacity. C \# development for online apps has problems with bandwidth capacity. The React Native programming language is compiled in $\mathrm{C} \#$ when created in an online application.

\subsubsection{Fuzzy Logic for C ++ Based Analytics Application} Analysis

The example of codes is written below based on to Jeong and Ramirez-Gomez (2017):

<bodyjscontroller="hS6RLb" jsmodel="utMpr"

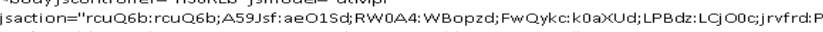

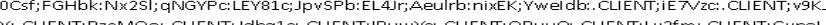

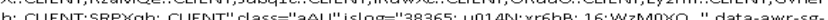
installed="true" =-<frametabindex=" -1 " style="position: absolute; width: 9 em; height: $9 e \mathrm{em}$; top: $99 \mathrm{em} ; "$ "></frame>>linkid="embedded_data_iframe" ><div style="font-size:0; color: white; z-inde

The example of codes is written below based on to Hoffman and Stroustrup (2016):

style="bottom:0; left:0; overflow:hidden; position:absolute; right:0; top:0" $><d$ div class="la i"><div style="animation: $1.7 \mathrm{~s}$ cubic-bezier(.17,0,.1,.87)1.2s kf-

s; background:\#fafbfb; border-radius:330px; height:660px;left:50\%;margin:-406px -

\subsubsection{C ++ Language Programming for Analyzing Data} Patterns in Database

Nowadays, the use of $\mathrm{C}++$ language programming has been widely using in various purposes, such as games, entertainment, and other purposes. The key points of the $\mathrm{C}++$ language program is it is able to learn autodidacts and able to learn via YouTube. Chatterjee,

et al. (2014: 24) have Thus, there are a lot of various purposes for $\mathrm{C}++$ language programming. Once, the purposes for $\mathrm{C}++$ language programming is to build a website that can store and manage the data into a single database. On the other perspective, the $\mathrm{C}++$ language programming is constructed to build a single key point, enhance related with Php Script that mostly related to server management script

The example of codes is written below based on to Hoffman and Benton (2016):

\#loading \{display:none\}

</style>-form id="null" action="?ui=html\&amp; zy=c" method="post"><input type="hidden"

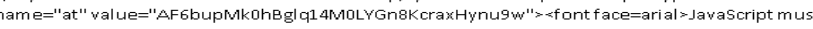
be enabled in order for you to use Mail in standard view.

Chatterjee, et al (2014: 23) argues s hearing with the pace of development of information and communication technology, basically, the use of technology is an integrated study of the study of information and communication technologies that provide opportunities for transformation in the application of the device in Indonesian learning.

According to Azar, et al (2015: 4). Therefore, the design for ICT for young learners must have occurred within the topic. On the other hand, the various design of artificial intelligence nowadays has intended to track back on the various technologies. On the other words, the Artificial Intelligence technology has given on the design of various activities. However, the design for language assessment must be designed with the appropriate language programming. Once, the design for language assessment to analyze the data is using the $\mathrm{C}++$ language program. Thus, the $\mathrm{C}++$ must occur in the design on language and tracking of the students' habits and activities.

\section{Conclusion and Suggestion}

\subsection{Conclusion}


The use of $\mathrm{C}++$ programming language is able to construct capabilities to Find similarity and pattern. However, the use of $\mathrm{C}++$ Language Programming is constructed to develop capabilities by the user to create and make it database relation within the files. Thus, the $\mathrm{C}++$ language programming is able to construct an application that makes interactive capabilities and design for each term. Therefore, the use of $\mathrm{C}++$ on the web requires hosting application, once it has been suggested by using Php My Admin as the basis for the $\mathrm{C}++$ application.

\subsection{Suggestion}

The use of $\mathrm{C}++$ applications despite paying attention to patterns and applied designs in terms of designing sequences requires corrective creation feedback apps that have a lot of requirements and are able to act as a text editor. In corrective feedback apps, more adopt a memory translator that, although it has multiple options, can first be used using existing ones like Google Translate, Bing and other applications and the second has another application that gives developers the opportunity to create their own creations on translation individual memory. Thus, the User Experience (UX) is an application based on and for users that are maintained.

\section{Acknowledgements}

This research was assisted by several person to develop analysis and synthesis development. First is Sandra Irawan M.A from Pusat TIK Universitas Negeri Malang (Center of Information and Communication Services State University of Malang) in creating simulation of Artificial Intelligence at learning management system on Universitas Negeri Malang internal servers, Aditya Nur Arrifin, President Director of Aryan Jaya Teknik Ltd who give review on artificial intelligence in practical settings in Indonesia and Arya Taufiqqurahman, Chief Executive Officer (CEO) of Trimitra Engineering, Ltd who gives the technical data on Artificial Intelligence in laboratory trials, especially in robotics and cloud computing on industrial organization factory. 


\section{VII.REFERENCES}

[10].

[1]. Azar, AT, \& Vaidyanathan, S. (Eds.). (2015). Guo, Computational intelligence applications in Z., modeling and control. Springer International Publishing.

[2]. Chatterjee, D., Bhattacharjee, P., \& Bhattacharyya, N. (2014). Development of methodology for assessment of the shelf-life of fried potato wedges using electronic processes: Sensor screening by fuzzy logic analysis. Journal of Food Engineering, 133, 23-29.

[3]. Chrysafiadi, K., \& Virvou, M. (2015). Fuzzy logic for adaptive instruction in e-learning environment for computer programming. IEEE Transactions on Fuzzy Systems, 23 (1), 164-177.

[4]. De Carvalho, D., Lee, J., Khan, A., Mazzara, M., Khazeev, M., Mustafin, R., ... \& Rivera, V. (2017). Teaching Programming and DesignbyContract. arXiv preprint arXiv: 1710.07956.

[5]. Dudin, MN, Frolova, EE, Lubenets, NA, Sekerin, VD, Bank, SV, \& Gorohova, AE (2016). The methodology of analysis and assessment of the risks of operation and development of industrial enterprises. Calitatea, 17 (153), 53.

[6]. Feraud, IS, Lara, MM, \& Naranjo, JE (2017, October). A fuzzy logic model to estimate safe driving behavior based on a traffic violation. In Ecuador Technical Chapters Meeting (ETCM), 2017 IEEE (pp. 1-6). IEEE.

[7]. Gal, P. (2018, June). JavaScript-only Parallel Programming of Embedded Systems. In THE 11TH CONFERENCE OF PHD STUDENTS IN COMPUTER SCIENCE (p.125).

$[8]$.

[9]. Gao, H., Qiu, Z., Wu, D., \& Gao, L. (2015,

Chen, W., Zhang, J., Ye, F., Liang, X., He, F., \& Guo, Q. (2017). Hazard assessment of the dangerous nature of cliffs based on the FuzzyAHP method: a case study of the Mogao Grottoes, China. Bulletin of Engineering Geology and the Environment, 76 (3), 10091020.

[11]. Hoddie, P., \& Prader, L. (2020). JavaScript for Embedded $\mathrm{C}$ and $\mathrm{C}++$ Programmers. In IoT Development for ESP32 and ESP8266 with JavaScript (pp. 25-126). Apress, Berkeley, CA.

[12]. Hoffman, S., \& Benton, M. (2016). C ++: C ++ and Hacking for dummies. A smart way to learn $C$ plus plus and beginners guide to computer hacking ( $\mathrm{C}++$ programming, $\mathrm{C}++$ for BeginnersVolume 2.

[13]. Hoffman, S., \& Stroustrup, B. (2016). C ++: A Smart Way to Learn $\mathrm{C}++$ Programming and Javascript (c plus plus, $\mathrm{C}++$ for beginners, JAVA, computer programming, hacking, exposed hacking). CreateSpace Independent Publishing Platform.

[14]. Jeong, JS, \& Ramírez -Gómez, Á. (2017). A GISBased Multilingual Assessment to Optimize Biomass Facility Sites with Parallel Environment-A Case Study in Spain. Energies, 10 (12), 2095.

[15]. Julián-Iranzo, P., Moreno, G., Penabad, J., \& Vázquez, C. (2015). A fuzzy logic programming environment for managing similarity and truth degrees. arXiv preprint arXiv: 1501.02034.

[16]. Karatop, B., Kubat, C., \& Uygun, Ö. (2015). Talent management in manufacturing systems using a fuzzy logic approach. Computers \& Industrial Engineering, 86, 127-136.

[17]. Khuankrue, I., Mankong, C., \& Tsujimura, Y. (2017, December). Fuzzy signature approach to clarification of subjectivity in the assessment of metacognitive skills transfer. In Teaching, Assessment, and Learning for Engineering (TALE), 2017 IEEE 6th International Conference on (pp. 389-392). IEEE. 
[18]. Korkin, S., \& Lyapustin, A. (2019). Matrix exponential in $\mathrm{C} / \mathrm{C}++$ version of vector radiative transfer code IPOL. Journal of Quantitative Spectroscopy and Radiative Transfer, 227, 106-110.

[19]. Šmitek, B. (2020). INTEGRATING MINIMOOCS INTO STUDY PROGRAMS IN HIGHER EDUCATION DURING COVID-19. FIVE PILOT CASE STUDIES IN CONTEXT OF THE OPEN VIRTUAL MOBILITY PROJECT. Human and Artificial Intelligence for the Society of the Future.

[20]. Vancsics, B., Szatmári, A., \& Beszédes, Á. (2020,

February). Relationship between the effectiveness of spectrum-based fault localization and bug-fix types in javascript programs. In 2020 IEEE 27th International Conference on Software Analysis, Evolution and Reengineering (SANER) (pp. 308-319). IEEE.

[21]. Wolf, D., \& Henley, AJ (2017). Make Web Pages Do Something Using JavaScript. In Java EE Web Application Primer (pp. 111-114). Apress, Berkeley, CA.

Cite this article as :

Ferril Irham Muzaki, "Indonesian Language Portfolio in Elementary Schools Based on C++, C\# and MySQL Server", International Journal of Scientific Research in Science and Technology (IJSRST), Online ISSN : 2395602X, Print ISSN : 2395-6011, Volume 7 Issue 6, pp. 263-272, November-December 2020. Available at doi : https://doi.org/10.32628/IJSRST207643 Journal URL : http://ijsrst.com/IJSRST207643 